\title{
A participatory approach to service- learning in creative arts education: a win- win learning opportunity for campus and community?
}

\section{Lesley Wood and Merna Meyer}

\begin{abstract}
Service-learning has been shown to be effective in preparing students to live and work in a diverse and rapidly changing society, especially when it is based on a democratic partnership between university students and community participants, resulting in mutually beneficial learning. Yet, in cases where the community is often regarded as less equal due to debilitating socio-economic circumstances, there is a real danger the engagement turns into more of a charity rendering experience, rather than promoting deep learning for all involved. This article reports on our attempts to create a service-learning experience that allowed students and community youth to learn with and from each other. Data were generated in four cycles of a participatory action research design, using visual, art and text-based strategies. The thematic analysis indicated that the process gave participants a better understanding of each other's lived realities; that it helped to level out unequal power relations; and that the reciprocal learning boosted development on personal and professional levels. The knowledge we share in this article will help others to know how to design and implement a valuable and mutually beneficial service learning experience not only in Creative Arts education; but in any discipline where students engage with community.
\end{abstract}

A Swahilli tale depicts the relationship between a monkey and a shark, a story about two creatures living in two worlds. The shark needs the heart of the monkey to give to his king who is ill and so invites the monkey on a journey with the ultimate aim of killing him, so that the king can live. The monkey agrees to go on the journey because he wants to learn and experience new things. However, the monkey finds out what the shark is planning and tricks him into taking him back to terra firma where he escapes from the shark, abruptly ending their brief relationship. Neither of them gained what they really wanted from the experience and both end up with a negative perception of the other and increased distrust. The clandestine motives of one character resulted in both parties going their separate ways with no real gain. Both were disgruntled that they had not benefitted from the relationship. 
Often attempts to conduct community engagement result in similar outcomes due to failure to clarify motives, interests and the purpose and process of the relationship (Hall, Jackson and Tandon, 2016). Piggot-Irvine (2012) calls for authentic collaboration between all partners when embarking on community-engaged activities. Internationally there are calls for service-learning experiences to shift from a "philanthropic" (Slamat, 2010, p.104), "paternalistic" (Butin, 2010, p.208), one-sided, interventionist approach to a more collaborative one, underpinned by a dialogic relationship (Freire, 1997), that encourages communication and discovery, indispensable to knowledge and understanding on how to work together to create a more socially just society. This study thus focused on creating knowledge partnerships (Mitchell and Rautenbach, 2005) between community participants and pre-service Creative Arts teachers to engage in art experiences where they could share their respective values, knowledge, and skills in order to learn from and with each other. By embedding art practices in community engagement projects, we aimed to open exchanges of mutual interest and reciprocal visions that would cause our relatively privileged, middle-class students to question their accepted beliefs about the 'other', to craft a better understanding of the human commonalities between all people, regardless of their demographic background. Local knowledge is generally not foregrounded in teacher education, as we still tend to 'train' teachers to work in well-resourced education contexts (Wood, 2014). By encouraging students and community youth to share art experiences towards a mutual goal, we hoped to counter the more usual approach where service is given to communities by artists (Helguera, 2011), in line with the call for new "'terms of engagement"' (Erasmus, 2009, p.5) between higher education and communities to foster knowledge democratization. Service-learning has not been included in the formal academic program of Creative Arts education at our institution, hence the need to establish the educational benefit it might hold. The study we initiated was part of a larger interdisciplinary community project and the task for our students was to engage with community youth to aesthetically enhance a plot of land designated as a recreational area in a local township. The main questions that guided our study were:

What can student and community participants learn from the process?

What aspects of the engagement process enhance the attainment of mutually beneficial learning outcomes? 
What recommendations can be made to inform the development of future service-learning initiatives in Creative Arts education programs and other disciplines?

We first explain how we conceptualize service-learning as a transformative pedagogy, using art to foster social engagement, before outlining the research methods. We then critically discuss the emerging themes in relation to literature and what implications they have for the inclusion of service-learning opportunities as an integrated educational experience in pre-service teacher education programs in particular, and undergraduate programs in general.

\section{Service-learning as a transformational pedagogy}

We draw on a critical, post- modern paradigm to understand service-learning (Rogers, Luton, Biggs, Biggs, Blignaut, Choles and Tangwe, 2013), with experiential learning (Schön, 1995) as the pedagogical foundation. Experiential learning foregrounds contextualization of the learning experience and allows exploration of the relational partnerships with a view to transforming epistemologies and ontologies, accepting social responsibility and recognizing the traditional knowledge base of communities (Schön, 1995). Kolb's (Kolb and Kolb, 2005) experiential theory permits a Mode 2 teaching and learning style, where dialogical engagement is encouraged, as opposed to the transference of undisputed disciplinary 'truths'. Critical theory views service-learning from an anti-foundational perspective (Butin, 2010) which aims to encourage questioning of norms, behaviors and assumptions. It emphasizes the political nature of education and involves a dialectical approach to problem-posing within complex social systems (Freire, 1985). These theories helped us to shift service-learning from the notion of 'expert help' by students towards the fostering of a democratically generated, reciprocal knowledge pool, created from the reflective dialogue between campus and community participants. All participants validated the decisions in the engagement process (Thornton, 2013), thus creating a more equal balance of power, or "democratic intimacy" (Freire, 1997, p.12) that promotes social change through relational experiences.

We expressly wanted to provide our students with an opportunity to dialogue with young people of similar age, but with a very different trajectory of life 
experiences. Unless student teachers undergo such boundary-crossing pedagogical encounters, how can we expect them to be inclusive teachers who understand not only the negative influence of a poverty existence on education, but also the assets that such youth bring to the educational project? They also need to recognize and incorporate valuable local knowledge into their teaching to make it more relevant to learners' lived realities (Higher Education Quality Committee (HEQC), 2006). We need teachers who are empathic, caring and respectful of all people, who see the potential in youth rather than the problems. We used the service-learning opportunity to disrupt previously held assumptions and open up a third space (Engeström, 2001) for the generation of knowledge that will better prepare both students and community youth for professional and personal roles in this unequal and socially unjust society. Art can be used to promote social engagement between persons who would otherwise never have had the opportunity to interact.

\section{Art practices to promote social engagement}

The defining elements of socially engaged art (SEA) (Helguera, 2011) include group relationships and exploration of collective experiences through art-based practices. Although the art itself was not the focus in the study, since neither groups were art specialists, it served as a mediating tool to encourage goal directed social interaction between two diverse groups of young people - a pedagogy that can be used in any discipline. As suggested by Helguera (2011), we sought to create a convivial atmosphere to promote collaboration and participation as the participants worked together to plan, design and implement their artistic interpretation of what was needed to beautify this particular community space. SEA praxis is normally staged outside typical art environments to include 'non-art' communities who are willing to engage in dialogue with others. This form of situational learning results in the generation of critical and experiential knowledge (Helguera, 2011), leading to better understanding of self and others. When university students enter complex and unfamiliar situations, social dynamics expressed through cultural codes can be misinterpreted, underestimated or ignored which results in both university and community partners feeling lost, uncertain of how to proceed or even leave them with a negative perception of the other. SEA necessitates an understanding of how interpersonal relations (e.g. power, dependence, conflict resolution, relationship building) can be 
negotiated between the parties involved. The conversations that took place between the participants in this study were aimed at arriving at common understandings on the given task (developing art work for the park), raising awareness about problems, debating particular issues and collaborating on a final product (Helguera, 2011). In most phases of the process, the conversations between the participants were the core source of meaningful and mutual knowledge generation. In the end, the pragmatic artifacts created reflected an understanding of the real needs of the community members - they painted large tractor tyres which they then embedded in the ground (so they were not stolen) to demarcate the open space and make it attractive to children as a play area (see Figure 1). Thus, through socially engaged art practices, they could agree on a solution that was aptly suited to this particular environment, rather than an abstract piece of art that would probably have been vandalized or stolen.

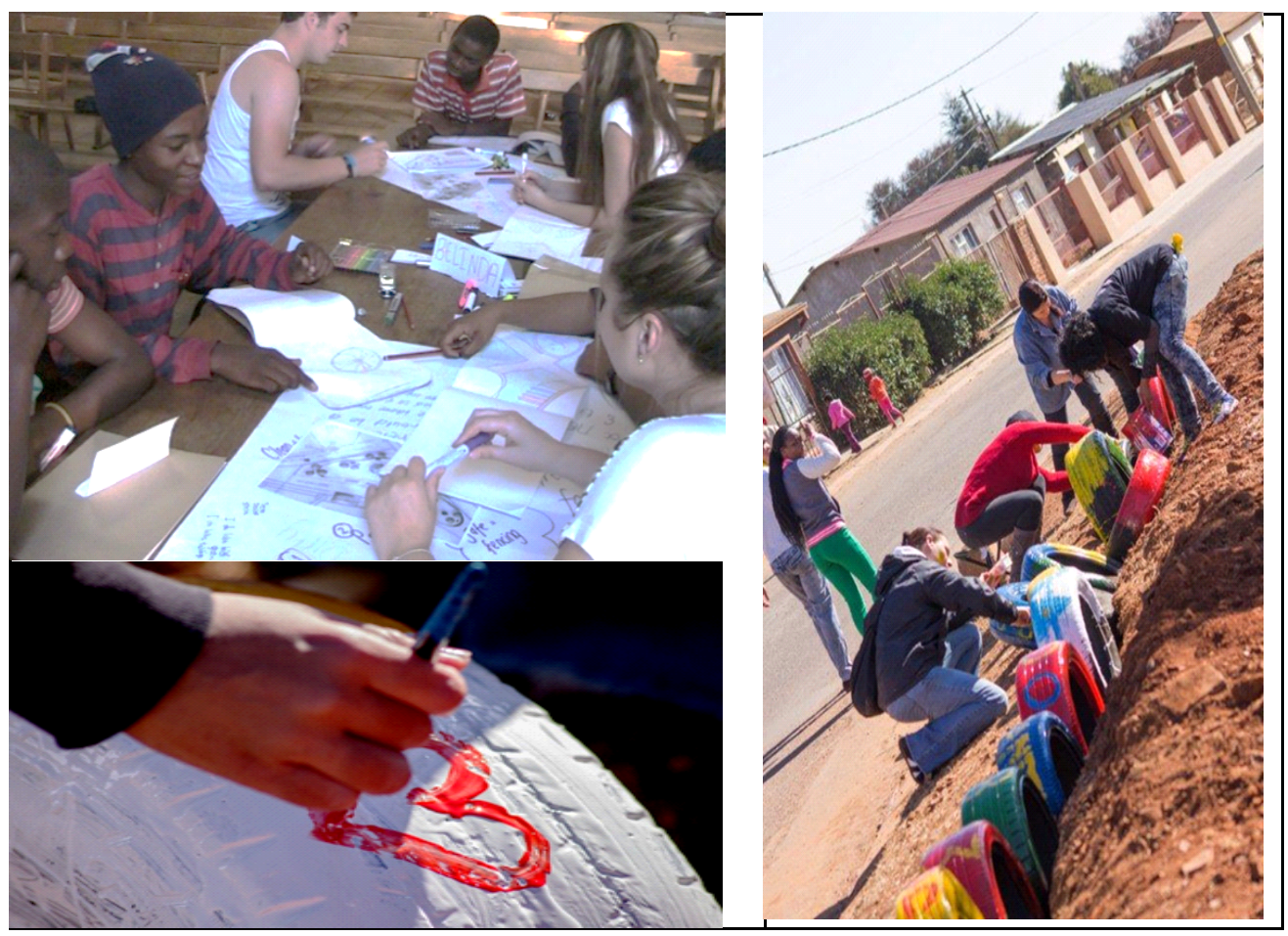

Figure 1: Participants collaborating on project 


\section{Methodology}

We opted for an action research design, since we wished to improve our understanding of how to make the service-learning experience more resonant of our transformational aims. We used Stringer's (2007) model of looking, thinking, acting and reflecting to inform the participative cycles of (i) relationship-building, (ii) planning (iii) skills application and (iv) reflecting, through which we guided the participants as reflected in Figure 1.

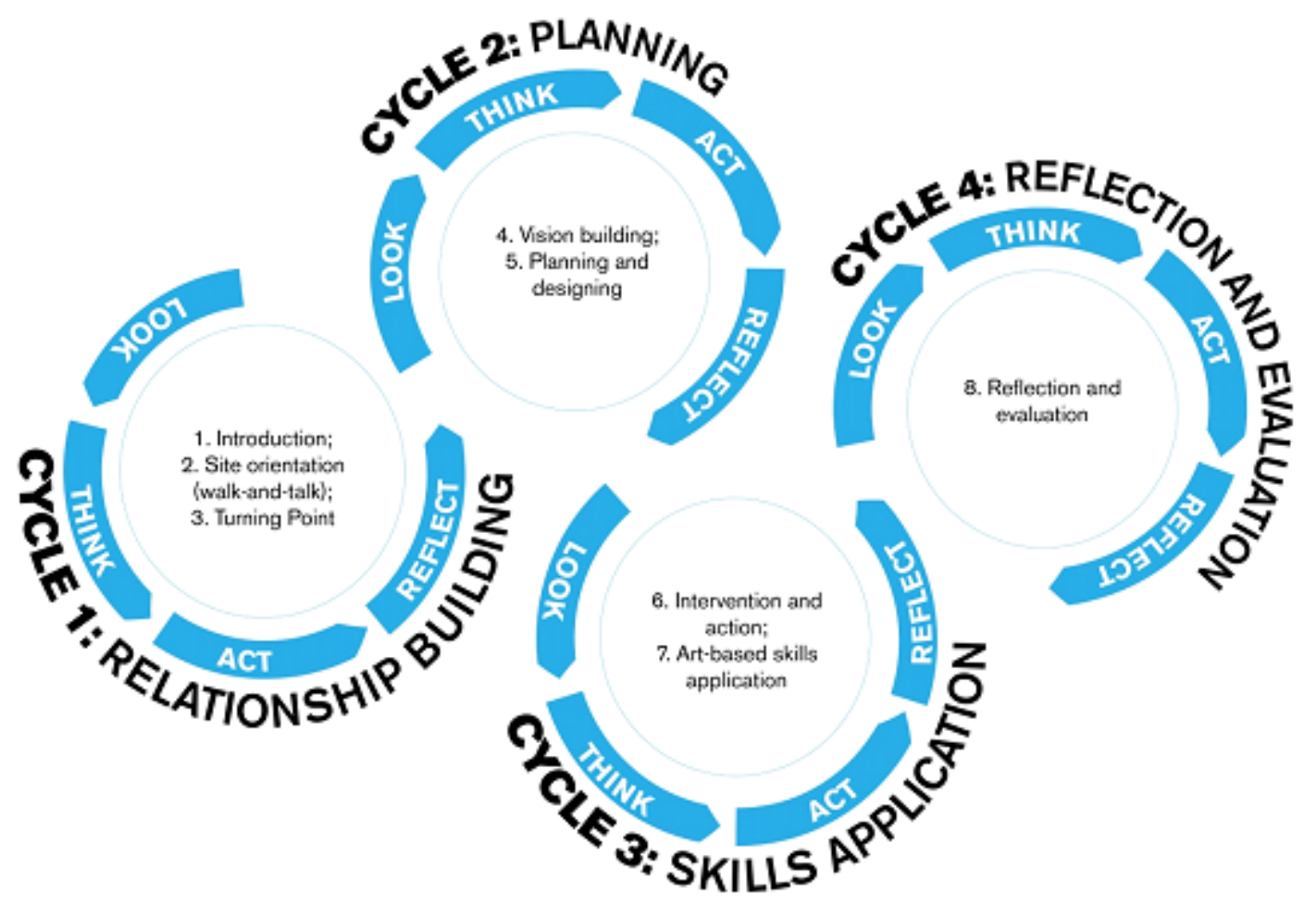

Figure 2: The research design followed 
We asked for volunteers from a third-year class of intermediate phase Creative Arts student teachers and two females and one male responded. We then asked community elders to help us to find community participants of similar age (18-21). Three males and one female who were still at school and one female who had completed her final school examination and was working part-time, volunteered. The campus participants were Afrikaans speaking; the community youth were Setswana/Sesotho speaking, therefore the lingua franca adopted was English which they could all speak to a certain extent. We chose intermediate phase students, who do not receive specialized art training, as we wished to avoid them appearing as 'experts'. Data generation was attained through eight practical, participatory activities (as outlined in Table 1) in a relational interactive process between participants. We also generated data in the form of field notes from observations and reflections on the process (Creswell, 2009). 


\section{Table 1: Data generation process}

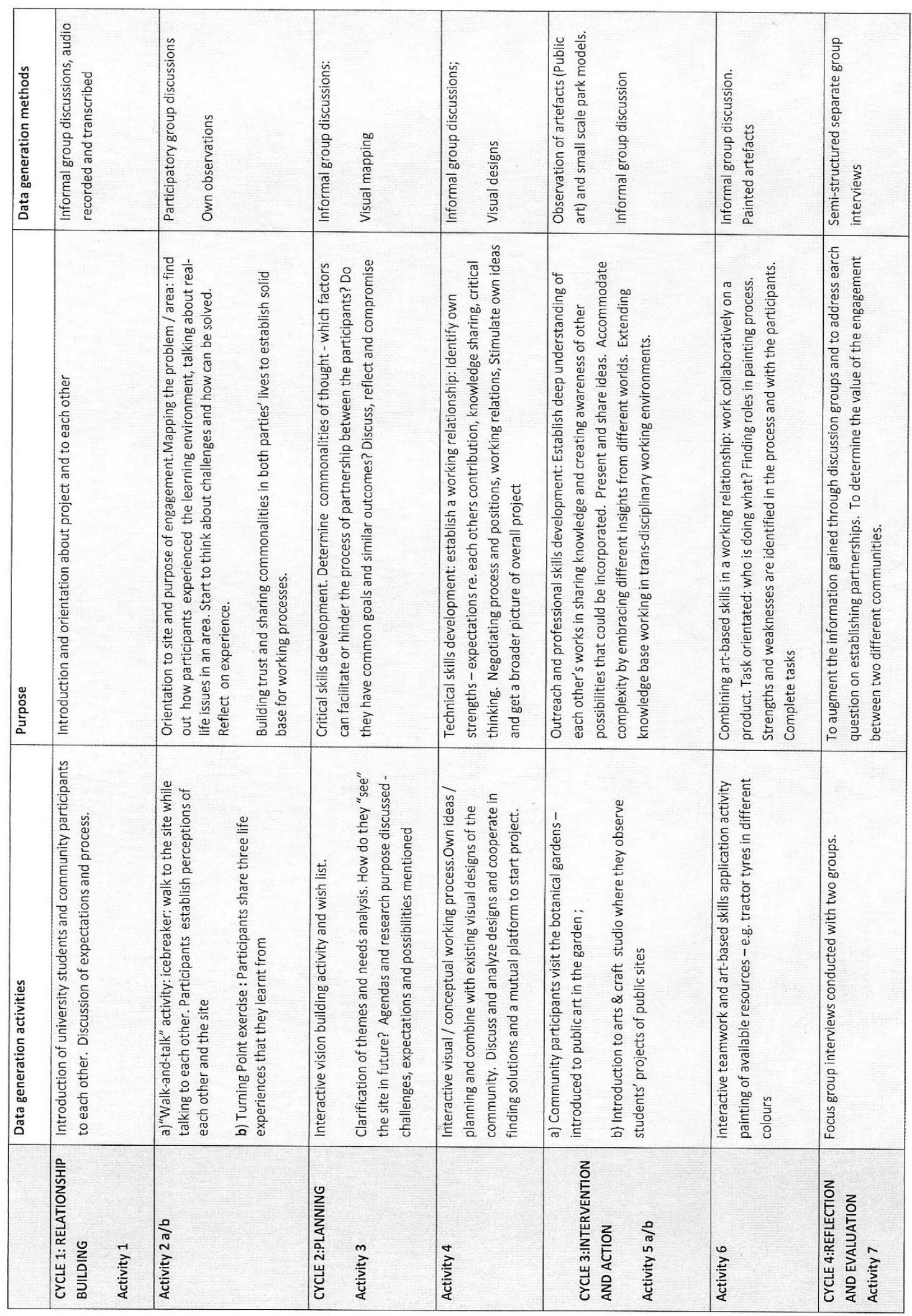


For the purposes of this paper, the visual and text-based data were thematically analyzed by both of us independently, before coming together to reach consensus (Niewenhuis, 2010). Triangulation of data sources, use of re-coding and full description of the research process increased trustworthiness (Creswell, 2009). Ethical clearance from the institution ensured the study adhered to the obligations of informed consent, voluntary participation and right to withdraw at any time. Participation by the students did not count towards any formal assessment.

\section{Discussion of findings}

Three main themes emerged from the data analysis that helped us construct answers to our research questions. We discuss the themes below, supported by verbatim extracts from the data and relevant literature. To identify the origin of the extracts we use the following codes: Cn (community participant); Sn (student participant).

\section{Theme 1: The process allowed participants to gain insight into each other's worlds and disrupt stereotypical assumptions}

The initial discourse of the two groups revealed their stereotypical perceptions of each other and the roles they would play in the study. The community participants perceived the students as "helpers" (C2) who would teach them everything, positioning themselves as 'non-experts' who had little to offer to the process, while the students were concerned primarily with their own learning and learning about the community youth, rather than with or from them:

It will be nice. . .because they are too smart $(\mathrm{C} 1) ; \ldots$. everything they coming with [bringing along] it's fine (C4); Then we can help each other. Like maybe, one of them could help with mistake [s we make]. . . (C3).

... I also want to learn about their cultures (S2); I also want to learn stuff about myself. . . What I can do and what I can't do. And to help them. Yes [laughs] (S1).

The interaction between the participants helped them to begin to question deep seated assumptions they had about each other, particularly on the side of 
the students. In our diverse and unequal society, being able to understand the experiences and perspectives of those from different backgrounds is a vital life-skill, all the more so for prospective teachers who wield an inherent power over the cognitive and value formations of learners (Bennell, 2004) and need to explore their own attitudes and values to be sure that they are not perpetuating divisive worldviews and practices. Both groups moved out of their comfort zones to participate in the engagement process, which helped them to shift their stereotypical thinking and tendency to 'other'. The students in particular were prompted to view learning differently, to "redefine who the 'servers' are in relation to the 'served' and how boundaries continue to keep these two groups apart" (Hayes and Cuban, 1997). Thus art was used as a mediator to disrupt thinking (Helguera, 2011), with the experiential learning approach providing a platform for dialogical engagement (Kolb and Kolb, 2005) towards better understanding of each other.

It could also be argued that the participants used stereotypical discourse in the beginning because they had to process a rather complex situation and this served to simplify "a complex environment", giving them a "cognitive schema" to process the situation (Dovidio, Hewstone, Glick and Esses, 2010, p.9). Towards the end of the engagement period, the students admitted that they had used an 'othering' discourse because they did not know how to address the community participants:

We don't know how to say the other, to say the children or the students or the people from the Ikageng, that is why we said the other people (S1).

Students started to become more aware of how they were perceived by the community participants and saw the need to offer support with the aim of assisting community participants to become proficient themselves:

I think I realised that we weren't necessarily there to help them, but just to support them in the things they want to do... So that they can help themselves (S3).

The views of students were initially somewhat patronizing, influenced no doubt by our deep rooted colonial and Apartheid history (Killen, Richardson and Kelly, 2010), assuming that life in the community was not pleasant: 
...the parents must create a safe place at their home, so that uhm, I just think that our parents are more protective, I can be wrong, over us, because I don't know why. But uhm, in our culture or my culture, we are not afraid to say something is wrong, like alcohol abuse or whatever. But to them it is quite normal; alcohol abuse, it's every second person (S2).

However, they gradually became more understanding of the community youths' reality and even expressed admiration:

I think the youth there grow up long before we are grown. They must be adults when they are actually still children, because they must take care of themselves or a younger brother or sister (S3).

An almost envious tone started to emerge as students began to reposition the community participants' life as freer than their own, which in turn led them to question their assumptions:

... I always thought it was the unsafest place, uhm, but it's just how they live. It, is not that unsafe as we people think it is, it's just. . .there is a stereotype over there, there is a stereotype about townships, well specific that area (S3).

Everything [in our lives] is planned for us but they take it as it comes, but they enjoy every day and they live full-out every day (S2).

People are products of individual cultures, moulded from the values and morals inculcated by families, friends, communities, educational institutions, and religious affiliations (Duncan and Brooks Taylor, 2013), and such "knowledge in the blood" (Jansen, 2009, p.4) can only be changed by interacting in a safe, yet challenging environment. The students compared their planned lives to the community participants' freer lifestyles which helped them to critically reflect on their social values and behavior to challenge their prejudicial attitudes and stereotypical expectations (Killen et al., 2010), a fundamental aim of critical theory.

As they interacted and learnt experientially through the relationship building and orientation exercises in the community setting, participants began to develop a higher level of empathy for each other's situation and showed signs 
of wanting to learn from each other. The students understood the importance of establishing a rapport with the community participants:

...we had to get to know each other more, and that, that, I think that makes it easier (S3); We had to understand what they feel, how they feel and how we feel (S1).

I wouldn't normally tell anyone about my feelings, but it came to an end that I had to express my feelings too. I was like trusting them, I had, I had this trust in them. . (C3).

Students began to compare their privileged lives to the harsher realities of the community participants, which prompted them to give community members more space to express themselves. Thus the art-based activities mediated a social exchange to strengthen personal relationships contributing to the building of trust, opening up spaces for meaningful conversations (Helguera, 2011). This allowed the community participants to take a more active part in the planning, design and creation of the artefacts:

They were always willing to, willing to do something ... because they showed up for every meeting, they were on time for the garden when we went there and they were open minded about everything (S1).

Participants started to acknowledge the value of opening up to each other's worlds, and that differences were not as deep as they imagined:

They teach me that if you are a people, you can do things, even with different cultures, you can make one group of people and discuss things, making good things (C4).

I was walking with the white people and the black people, we are just tell them about this park, this park, they are to, it will be nice, and our communities will be watching their park, . . see that people can walk together there, white and black $(\mathrm{C} 1)$.

I think all the youth experience the same situations, because it doesn't matter what your colour is, or your gender or something. Everyone has to deal with drugs, and alcohol, and death, and divorce. So I think it is the same everywhere (S1). 
Becoming part of a group has potentially adaptive dimensions in terms of nurturing an individual and forming a caring society (Dovidio et al., 2010), something that is especially important for prospective teachers to learn. Through such interaction, deep-seated assumptions are troubled and the individual is challenged to rethink how they relate to others.

\section{Theme 2: The PAR process shifted power relations}

The students associated leadership with confidence and regarded these two qualities as important attributes in the interactive process with the community participants. The evidence indicated that they were pleased that the initial quietness of the community participants as "passive acceptors of domination" (Freire, 1985, p. 81) changed during the process and that the community participants started to voice their opinions:

They were afraid to tell their ideas, because they didn't know if it was wrong or right. . .they thought automatically that we must always be right and they wrong (S2).

I at first thought maybe they don't have that, uhm, leadership qualities, but that is not the case. . .think it was a case of being shy (S3).

It became clear that the community participants initially positioned the students as more knowledgeable than them. The students also initially thought they had better ideas and the community participants were happy to follow their lead. The PAR process, underpinned by a critical paradigm, aims to promote a more liberated, non-hierarchic orientation that emphasises dialogic conversations during the working process (Freire, 1985). This happened on a micro-level between students and community members, as the students began to do less and listen more, giving the community youth more space to display their knowledge and skills.

Power is relational and changes as relationships change (Duncan and Brooks Taylor, 2013). The students started to question the value of 'expert' power, showing preference for a more democratic leadership style:

Everybody gets a chance to talk, ... .everybody decides what this person must do and he must also decide. . (S1). 
Maybe in a group you must, uhm, not necessarily have a group leader, but everybody gets a chance to uh, to talk and then everybody decides what this person must do and he must also uhm, decide if he wants to do it. Everybody must all agree what the person must do and he should also (S3).

The students started to value the collaborative working process as a means to overcome shyness and to encourage mutual engagement. The accommodating attitude of the students reflected their willingness to listen and encourage talk - much needed qualities for teachers. They acknowledged their own potential and expressed it honestly, but also discouraged dominant positions (Birks and Mills, 2011), treating everybody as equal partners and trying to create a positive interactive experience for all. They effectively moved closer to a shared form of leadership where they learned to negotiate their positions instead of taking dominant positions and forcing their viewpoints on the other participants.

\section{Theme 3: Participants experienced personal and professional development through the interactive process}

Students and community participants learned to share their life experiences as well as their visions for the park, engaging in learning experientially through a variety of interactive activities. Meaningful service-learning provides a sense of purpose, connection, relevance, and usefulness, which requires time and effort from all and includes everybody's voices in the planning, implementation, and evaluating phases (Duncan and Brooks Taylor, 2013). The participatory methodology enabled participants to work collaboratively in groups, acquiring oral and written communication skills, and opened up leadership possibilities which contributed to their personal and professional development.

The experience was a somewhat humbling one for the middle-class students, leading to a realisation that they needed to be more empathic:

And they taught me, uh, cause I saw how they are, their living, and uhm, they learned me to be more appreciative of what I have today and not complain so much (S3). 
We had to understand what they feel, how they feel and how we feel (S2.)

The ability to empathise with others and accept personal responsibility for contributing to a better society are essential skills for teachers to possess and model to learners (Binkley, Erstad, Herman, Raizen, Ripley and Rumble, 2010). Other professional and personal competencies such as communication, collaboration and patience were also improved through their interaction in the group.

The students affirmed that the research process helped them to become more tolerant and aware of the importance of understanding diversity:

I had to learn patience, because when we try to explain something to them like the idea of the tyres, they don't understand on the spot (S1).

I think we also learned from them, how to interact with different cultures and how to approach a project like this. How to share. (S2)

Acceptance of diversity requires excessive self-evaluation, especially in relation to others who may have been regarded as inferior in terms of class, race, gender or other groupings (Freire, 1997).

Language was one of the communication barriers they had to address during the process. Language is a powerful tool which can create or decimate, empower or oppress and is one of the main barriers to learning that students will encounter in the multicultural classroom. One of the community participant's poor command of English necessitated constant translation by another community member, but this sensitized them to the need to find creative solutions to minimize the barrier:

You can, in a class room, and with them as well, you can use somebody that understands both languages quite well. Their language and English and Afrikaans, doesn't matter, so that they can translate it to them or to you (S3).

They learnt to use visual material and physical examples such as the mock-ups of the park to clarify concepts: 
I think, uhm, they got a better understanding when they saw the pictures and the uh, projects, this miniature sculptures that we made. I think they then only realised, or they got a better, uhm understanding of what, what we are trying to do (S2).

The students recognised the value of practical applications to complete tasks act as substitutes for spoken words, providing mediating possibilities towards a better understanding of the concepts and specific problems which in turn enabled shared completion of the tasks.

Participation in this project also exposed the students to many other sources and aids that could be applied in their future classroom teaching. The collaborative brainstorming during the vision-building exercise involved a number of communication skills: talking, listening, writing, looking, and drawing. The students did not just hear, but listened intently while they wrote down suggestions made by the group during the vision-building discussions. The community participants recommended that the students write on the charts as they wrote more quickly. Allowing those with stronger writing skills to write, enabled the others to talk and think about possible solutions.

Drawing pictures and using different coloured text enhanced the community participants' understanding of the concepts. The students showed appreciation for the community participants' skills in the process (they know how to cut the edges (of the designs] when they paint.) They also realised how they could apply this learning in their future teaching:

I think it also helps to realise that one day when we work, we must, uhm, involve the community and how to approach a project like this. So if we, as teachers, want to do something like this in the community, we must be able to go and not be afraid and put the learners at ease, because we know it's safe and it is not so bad) (S2).

Thus, the pre-service teachers learned first-hand how to teach in diverse contexts. The students also gained a better understanding of time management and how to apply themselves strategically during the engagement process, by prioritising tasks, an essential quality in a teaching career.

Because you need a lot of time on a project like this, so, and everybody just have that much time in a day. So, you must know what is most important to do first, get it done and this is the time you have for it. So you must be efficient in the time you have (S2). 
The students learned to handle unexpected variables and showed willingness to compromise, becoming flexible in unforeseen circumstances. They also became independent role-players, free to voice their opinions in a critical and reflexive way.

In placing emphasis on the personal, the pre-service teachers were challenged to think beyond rigid subject definitions and to consider the place of creativity and the creative processes involved in all areas of knowledge and skills development, not just those traditionally labelled as 'arts' or 'creative subjects'.

The community participants also benefitted from the engagement as they became involved in problem-solving activities and recognised the value of project planning:

Ja, I've learned that before we do a park, we must come up with a plan first, before doing everything" $(\mathrm{C} 1)$.

... if you are going to make a park, you must make sure that you've got nice plans, that tomorrow that people looking at that park can feel joy (C2).

The learning helped to build self-confidence as they started to express themselves in spontaneous and creative ways; they became engaged in problem-solving activities such as the planning and designing activities of the park, and started to discover their own potential and talents. They also started to exercise some choices in the planning of the artwork which implied that they were venturing out of their private world and comfort zones to search for meaning not only in their own lives but also with others (Duncan and Brooks Taylor, 2013):

...he says that the project changed him in drawing, he didn't know how to draw or paint. So now he was amazed that he can do little things of art (C3 translating for $\mathrm{C} 2$ ).

The process presented opportunities for all the participants to demonstrate their creativity, a concept increasingly foregrounded in discussions about learning. Creativity is not only concerned with highly creative acts, but also pertains to how we live our lives. It relates to how we identify and actively initiate or respond to the challenges and context in which we find ourselves, 
how we innovate, make choices, or effect changes (Dymoke, 2013). The community participants started to gain confidence in their own abilities and on a small scale started to develop their talents. Various creative characteristics were noticed in their interaction with art; they became curious, noting all the different types of public art; started to elaborate on their ideas, paying attention to detail and to make drawings of their observations. The engagement process helped the community participants to stretch themselves, to take small steps in discovering their own hidden potential, and to become less naive and more critical and dialogical in their thinking (Freire and Macedo, 1995).

Painting the tyres together during the last activity was another group exercise which benefitted the community participants allowing them to socialise, mixing work with play. The students started to move more into the background, allowing the community participants to take over and do the painting work. With this slight behavioural change, we noticed that the students were allowing the community participants to empower themselves by giving them a chance to work on their own with the paint and brushes. Both groups recognised each other's' strengths and applied themselves in collaborative ways to complete the tasks. Some painted, others mixed and stirred the coloured paints. They were talking, listening to music, and joking getting to know each other on a more personal level:

I liked it when we actually painted, because then we started to speak about each other's personal lives as well (S2).

He says that he is going to tell the others that it is all about designing and making art, so they should enjoy it ... he is going to tell the others ... they talk a lot, they interact with the students $(\mathrm{C} 3$ translating for $\mathrm{C} 1)$.

The painting activity allowed technical skills to surface as the participants simplified complex ideas into ones that were practical and do-able. They were able to demonstrate their technical abilities and their power to contribute in a non-threatening setting (Duncan and Brooks Taylor, 2013). 
Unlike the monkey and the shark story, which ended in increased distrust, disgruntlement and no lasting benefit for either party, the participants in this project did form a working relationship that allowed them to learn and grow in ways that can only enhance their future engagement as citizens and teachers. We embarked on this study to find out how a participatory service-learning experience in a creative arts program could enhance both student and community participant learning. Based on our findings, we can conclude that a participatory process is well suited for this purpose, as it is grounded in values that foster knowledge partnerships, rather than positioning the validity of one group's knowledge as superior. Respect, shared power, collaboration and democratic decision-making helped all the participants to critically reflect on their previously unquestioned assumptions about themselves, the 'other' and what implications these held for their future interaction as citizens and professionals. Our own critical reflection on the process has revealed a number of lessons that will add to the body of knowledge about the use of arts-based practices to engage students and community in mutually beneficial learning experiences that will promote the embodiment of values that underpin a socially just society.

We learnt that it is important to introduce relationship building exercises as a basis for engagement with the art process of ideas formation, planning, design, making, and reflecting. Unless this is done, the limited time allowed by the academic syllabus will make true engagement difficult. There is also a need to provide various art-based practices and art forms so that participants can choose between the different activities and apply their own artistic abilities which can range from merely observing and appreciating, to drawing, painting, making, or assembling. Similarly, the art-based process should not be approached rigidly, but should be flexible according to the needs of the participants and their levels of understanding. The process should determine the end-product which may very well be different from the initial ideas and planning at the beginning. It is vital to accommodate a variety of hands-on activities to improve the participants' various creative and communicative skills, rather than promote domination by a few skilled participants. Finally, we also recommend developing some tools to help participants regularly reflect on their experiences, rather than relying on them being able to compose their own reflections, something that they all struggled to do. This study has thus provided a needed working methodology, applicable to any discipline, that can be added to the array of existing service-learning strategies. 
However, working in a participatory way presents its own challenges. It is time-consuming, since students and community members have to first form a working relationship before they can focus on the project per se; language and cultural differences have to be navigated and negotiated; and transport costs have to be accommodated. If the service-learning component of a module is not compulsory, there is the risk that most students will choose not to participate, as was the case in this study. However, the benefits of such an experience offer strong justification of why more undergraduate programs need to include such a component in their initial design.

The evidence we presented in this article supports our claim that the participatory service-learning experience helped to generate experiential knowledge that led to better understanding of self and others. This can only benefit the participants and ultimately society, as they hopefully share and embody this learning within their families, their social circles and their workplaces. Participatory service-learning experiences thus hold the potential to influence social change towards a more inclusive society. Through creative arts-based practices, the students and community members were introduced to dialogical processes, moving away from learning in campus-based classrooms towards creation of contextual knowledge which is purposeful, meaningful and responsive to social challenges. Hopefully, the introduction of such learning experiences into pre-service teacher programs, and undergraduate programs in general, will help to close the gap between the two worlds of the monkey and shark, leading to a deeper understanding of diversity and the importance of using education to promote reciprocal learning and collaboration towards a better world - a win-win situation for all.

\section{Acknowledgement}

Funding: An NRF community engagement grant (Grant No. 82623) enabled this research. Any opinions, findings or conclusions are those of the authors and the NRF cannot be held liable hereto.

\section{References}


Bennell, P. 2004. AIDS in Africa: three scenarios for the education sector. Report prepared for the UNAIDS project, AIDS in Africa: scenarios for the future. Geneva: UNAIDS.

http://www.eldis.org/fulltext/UNAIDSscenariosfinal.pdf [15 October 2013].

Binkley, M., Erstad, O., Herman, J., Raizen, S., Ripley, M. and Rumble, M. 2010. Defining 21st century skills. Melbourne: University of Melbourne.

Birks, M. and Mills, J. 2011. Grounded theory: a practical guide for authors. London: Sage.

Butin, D.W. 2010. Service-learning in theory and practice: the future of community engagement in higher education. New York: Palgrave-Macmillan.

Creswell, J. 2009. Research design: qualitative, quantitative and mixed methods approaches (3rd ed.). Thousand Oaks, CA: Sage.

Dovidio, J.F., Hewstone, M., Glick, P. and Esses, V.M. 2010. Prejudice, stereotyping and discrimination: theoretical and empirical overview. In Dovidio, J.F., Hewstone, M., Glick, P. and Esses, V.M. (Eds). The SAGE handbook of prejudice, stereotyping and discrimination. London: Sage, pp.3-28.

Duncan, J. and Brooks Taylor, T. 2013. Coming the full circle: a guide to service-learning. San Diego, CA: Cognella.

Dymoke, S. 2013. An overview of learning. In Dymoke, S. (Ed.). Reflective teaching and learning in the secondary school. Los Angeles, CA: Sage. pp.47-72.

Engeström, Y. 2001. Expansive learning at work: toward an activity-theoretical reconceptualisation. Journal of Education and Work, 14: pp.133-156.

Erasmus, M. 2009. Strengthening service-learning collaboration through community-based research. Stellenbosch: Division for Community Interaction.

Freire, P. 1985. The politics of education: culture power and liberation. Westport, CT: Bergin and Garvey. 
Freire, P. 1997. Pedagogy of the heart. New York: Continuum.

Freire, P. and Macedo, D. 1995. A dialogue: culture, language, and race. Harvard Educational Review, 65: pp.377-403.

Hall, B.L., Jackson, E.T. and Tandon, R. (Eds). 2016. Knowledge, democracy and action: Community-University research partnerships in global perspectives. Oxford: Oxford University Press.

Hayes, E. and Cuban, S. 1997. Border pedagogy: a critical framework for service learning. Michigan Journal of Community Service Learning, 4: pp.72-80.

Helguera, P. 2011. Education for socially engaged art: materials and techniques handbook. New York: Jorge Pinto Books.

Higher Education Quality Committee. 2006. A good practice guide and self-evaluation instruments to manage the quality of service learning. Pretoria: Council on Higher Education.

Jansen, J. 2009. Knowledge in the blood. Stanford, CA: Stanford University Press.

Killen, M., Richardson, C.B. and Kelly, M.C. 2010. Developmental perspectives. In Dovidio, J., Hewstone, M., Glick, P. and Esses, V.M. (Eds). Prejudice, stereotyping and discrimination: theoretical and empirical overview. London: Sage, pp.97-114.

Kolb, A.Y. and Kolb, D.A. 2005. The Kolb learning style inventory - Version 3.1: Haygroup, MA: Experience Based Learning Systems.

McKinney, B.L. 2011. Therapist's perceptions of walk-and-talk therapy: a grounded study. Unpublished master's thesis. New Orleans: University of New Orleans.

Mitchell, R. and Rautenbach, S. 2005. Questioning service-learning in South Africa: problematising partnerships in the South African context. A case study from the University of KwaZulu Natal. South African Journal of Higher Education, 19: pp.101-112. 
Niewenhuis, J. 2010. Qualitative research designs and data gathering techniques. In Maree, K. (Ed.). First Steps in Research. Pretoria: Van Schaik, pp.97-114.

Piggot-Irvine, E. 2012. Creating authentic collaboration: a central feature of effectiveness. In Zuber-Skerritt, O. (Ed.). Action research for sustainable development in a turbulent world. Bingley, UK: Emerald Books, pp.89-106.

Rogers, K.H., Luton, R., Biggs, H., Biggs, R., Blignaut, S., Choles, A.G. and Tangwe, P. 2013. Fostering complexity thinking in action research for change in social-ecological systems. Ecology and Society, 18: pp.31-39.

Schön, D. 1995. The reflective practitioner: how professionals think in action. London: Maurice Temple Smith.

Slamat, J. 2010. Community engagement as scholarship: a response to Hall. In Community engagement in South African Higher Education. Kagisano, 6. Pretoria: Council on Higher Education. pp. 104-114.

Stringer, E.T. 2007. Action research. Thousand Oaks, CA: Sage.

Thornton, A. 2013. Artist, researcher, teacher: a study of professional identity in art and education. Chicago, Ill.: Intellect.

Wood, L. 2014. Action research for the 21st Century: exploring new educational pathways. South African Journal of Higher Education, 28: pp.660-672. 
Lesley Wood

Faculty of Education Sciences

North-West University

lesley.wood@nwu.ac.za

Merna Meyer

Faculty of Education Sciences

North-West University

merna.meyer@nwu.ac.za 